\title{
Soluble intercellular adhesion molecule-1 for stable and acute phases of idiopathic pulmonary fibrosis
}

\author{
Ryo Okuda ${ }^{1,2^{*}}$, Hidekazu Matsushima' ${ }^{1}$, Kazutetsu Aoshiba² ${ }^{2}$ Tomohiro Oba' ${ }^{1}$ Rie Kawabe ${ }^{1}$, Koujiro Honda \\ and Masako Amano'
}

\begin{abstract}
The levels of soluble intercellular adhesion molecule-1 (SICAM-1) have been reported to increase in patients with idiopathic pulmonary fibrosis. However, the utility of sICAM-1 has not been reported in detail. The aim of this study was to investigate whether sICAM-1 was a useful biomarker for stable idiopathic pulmonary fibrosis (IPF) and early phase of acute exacerbation of IPF. The patients who were diagnosed with IPF between 2013 and 2015 were enrolled. The levels of sICAM-1 and other interstitial pneumonia markers were measured. In this study, 30 patients with stable IPF and 11 patients with acute exacerbation of IPF were collected. Mean sICAM-1 levels were $434 \pm 139 \mathrm{ng} / \mathrm{mL}$ for the stable phase of IPF, $645 \pm 247 \mathrm{ng} / \mathrm{mL}$ for early phase of acute exacerbation of IPF, $534 \pm 223 \mathrm{ng} / \mathrm{mL}$ for connective tissue disease-associated interstitial pneumonia, $221 \pm 42$ for chronic obstructive pulmonary disease, and $150 \pm 32 \mathrm{ng} /$ $\mathrm{mL}$ in healthy volunteers. For the stable phase of IPF, sICAM-1 levels correlated with Krebs von den Lungen-6 (KL-6) ( $r$ value: $0.41 ; p$ value: 0.036 ). Mean sICAM-1 levels were significantly higher in patients with early phase of acute exacerbation of IPF than with stable phase of IPF $(p=0.0199)$. Multiple logistic analyses indicated that the predictors for early phase of acute exacerbation of IPF were only sICAM-1 and C-reactive protein (odds ratio: 1.0093; 1.6069). In patients with stable IPF, sICAM-1 levels correlated with KL-6; sICAM-1 might be a predictive indicator for prognosis. In the early phase of acute exacerbation of IPF, sICAM-1 might be more useful for diagnosis than other interstitial pneumonia markers.
\end{abstract}

Keywords: ICAM-1, Idiopathic pulmonary fibrosis, Acute exacerbation, KL-6, SP-D

\section{Background}

Intercellular adhesion molecule-1 (ICAM-1) is a glycoprotein with a molecular weight of $80-110 \mathrm{kD}$ belonging to the immunoglobulin superfamily. Stimulation of inflammatory cytokines such as interferon and interleukin (IL)-1 leads to expression of ICAM-1 in vascular endothelial cells, tracheal epithelial cells, and fibroblasts within a few hours (Munro et al. 1989; Hubbard and Rothlein 2000; Vogetseder et al. 1989). As the expressed ICAM-1 is involved in adhesion to white blood cells (WBCs), it is considered to be a protein involved early

\footnotetext{
*Correspondence: b980013@yahoo.co.jp

${ }^{1}$ Department of Respiratory Medicine, Saitama Red Cross Hospital, 8-3-33

Kami-ochiai, Chuo-ku, Saitama 338-8553, Japan

Full list of author information is available at the end of the article
}

in the immune response (Albelda et al. 1994). As some of the expressed ICAM-1 is released into the circulating blood, measurement of soluble ICAM-1 (sICAM-1) levels in blood makes it possible to estimate ICAM-1 expression in the tissue.

For example, sICAM-1 levels have been reported to be increased in many inflammatory diseases such as infections, autoimmune diseases, and allergic diseases (Greve et al. 1989; Davies et al. 1992; Wegner et al. 1990). Furthermore, sICAM-1 levels have been reported to increase in pulmonary diseases, including chronic obstructive pulmonary disease (COPD), idiopathic pulmonary fibrosis (IPF), and connective tissue disease-associated interstitial pneumonia (CTD-associated IP) (Risse et al. 1994; Richards et al. 2012; Hasegawa et al. 2014). Few studies have compared sICAM-1 levels in different pulmonary

\section{垈 Springer}


diseases. Although Krebs von den Lungen-6 (KL-6) and surfactant protein D (SP-D) are used clinically in Japan as prognostic markers for IPF (Yokoyama et al. 2006; Takahashi et al. 2000), few studies have investigated the relationship between these and SICAM-1 in patients with IPF. We investigated these questions in this study.

Acute exacerbation of IPF is a disease with a poor prognosis in which new ground-glass opacities and infiltrates in both lungs and rapid respiratory failure appear in patients with chronic IPF (Kondoh et al. 1993). The Japanese guidelines state that blood KL-6, SP-D, C-reactive protein (CRP), and lactate dehydrogenase (LDH) are reference markers for acute exacerbation of IPF. As sICAM-1 levels increase in the early stages of inflammation, we estimated that SICAM-1 could become a biomarker for early phase of acute exacerbation of IPF.

\section{Methods}

\section{Subjects}

The patients who were diagnosed with IPF, CTD-associated IP, and COPD at Saitama Red Cross Hospital between July 2013 and July 2015 were enrolled in this study. IPF was diagnosed according to the following criteria: The patient was 50 years or older and conformed with the 2011 American Thoracic Society/European Respiratory Society IPF statement (Raghu et al. 2011); highresolution computed tomography (CT) images usually showed usual interstitial pneumonia (UIP) or possible UIP, and UIP caused by collagen disease, hypersensitivity pneumonitis, or drug-induced pneumonia was clinically excluded. For CTD-associated IP, two collagen disease specialists and two respiratory disease specialists at Saitama Red Cross Hospital had diagnosed CTD-associated IP based on physical findings, blood tests, and highresolution $\mathrm{CT}$ images.

"Stable IPF" was defined as patients with IPF who are stable for 2 months before the examination. In stable IPF, sICAM-1, KL-6 (reference range 0-500 U/mL), SP-D (reference range $0-110 \mathrm{ng} / \mathrm{mL}$ ), CRP (reference range 0-0.5 mg/dL), LDH (reference range 119-229 UI/L), and WBCs (reference range $3100-8800 / \mu \mathrm{L}$ ) were measured. Similarly, sICAM-1 was measured in healthy volunteers and patients with CTD-associated IP and COPD.

The diagnosis of acute exacerbation of IPF was based on the Japanese guidelines. Hence, after excluding other diseases such as obvious infections or heart failure, acute exacerbation of IPF was diagnosed based on the presence of all of the following: Increased severity of dyspnea, high-resolution CT findings showed honeycomb lung and new ground-glass appearances and infiltrates, and a decrease in partial pressure of oxygen in arterial blood of $10 \mathrm{mmHg}$ or greater. On the day when acute exacerbation of IPF was diagnosed, blood sICAM-1, KL-6, SP-D, et al. were measured. Patients for which blood was collected on the first day of acute exacerbation of IPF were defined as "AEx IPF". Almost AEx IPF cases underwent repeat measurements of sICAM-1 levels in the stable phase before or after acute exacerbation of IPF. All the blood samples in this study were centrifuged after clot formation. The serum samples were stored at $-20{ }^{\circ} \mathrm{C}$ prior to analysis. Serum levels of ICAM-1 were measured by enzyme-linked immunosorbent assay (SRL Inc., Tokyo, Japan). This study was approved by the institutional review board of the Saitama Red Cross Hospital. Written consent was received from all patients.

\section{Immunohistochemical and immunofluorescence staining}

Lung tissue samples were taken during surgery or autopsy performed at Saitama Red Cross Hospital in the past. Non-cancerous lung tissue samples were selected (two cases in each group) from patients of lung cancer with stable IPF, CTD-associated IP, and COPD receiving lung surgery. Autopsy lung tissue samples from AEx IPF cases (two cases) were used. AEx IPF and COPD lung tissue was taken from patients different from those in which serum sICAM-1 levels were measured. Resected tissue was embedded in paraffin after immersion fixation for $4 \mathrm{~h}$ in $10 \%$ formalin. Lung tissue was cut into $3 \mu \mathrm{m}$-thick slices. The use of the tissue samples was approved by the ethical review board of our hospital.

Lung tissue underwent immunohistochemical staining using a fully automated immunohistochemical stainer (Ventana BenchMark GX, Ultra View DAB: Roche Diagnostics International Ltd., Tokyo, Japan). For antigen activation, specimens underwent heat processing $\left(95-100{ }^{\circ} \mathrm{C}\right)$ for $60 \mathrm{~min}$ in ethylenediaminetetraacetic acid buffer solution ( $\mathrm{pH}$ 8.5) and we used rabbit polyclonal antibody against intracellular adhesion molecule-1 (Santa Cruz Biotechnology INC., Texas, the USA: 1:4000 dilution) as the primary antibody. For the horseradish peroxidase reaction chromogenic substrate, 3,3'-diaminobenzidine and compared nuclear staining with hematoxylin were used.

Lung tissue also underwent manual immunofluorescence staining. Paraffin-embedded lung tissue was deparaffinized, hydrated and autoclaved in citrate acid buffer (pH 6.0, $121^{\circ} \mathrm{C}$ for $15 \mathrm{~min}$ ). Bovine serum albumin (3\%) was used to block non-specific hydrophobic binding for $30 \mathrm{~min}$ and we used rabbit polyclonal antibody against ICAM-1 (1:400 dilution) as the primary antibody for $1 \mathrm{~h}$. Secondary antibody with Alexa Flour 488-conjugated anti-rabbit IgG (Abcam Plc., Cambridge, UK) and counterstain with DAPI were used. 


\section{Statistical analysis}

The unpaired $t$ test was used for comparisons between two groups. To investigate the correlation between sICAM-1 and other interstitial pneumonia markers, Spearman's rank correlation coefficient was used. Items suspected to be related to early acute exacerbation (sICAM-1, KL-6, SP-D, LDH, CRP, and WBC) were evaluated using univariate and multivariate logistic regression analyses. The analysis was performed with the Excel Statistics software (SSRI Co., Ltd.).

\section{Results}

For the 30 patients with stable IPF, mean percentage forced expiratory vital capacity (\%FVC) was $78.4 \%$ and percentage diffusing capacity of the lungs for carbon monoxide (\%DLco) was $74.9 \%$, indicating many patients with mild IPF (Table 1). There were seven patients with CTD-associated IP, six patients with COPD, and seven healthy volunteers. Mean sICAM-1 levels were $432 \pm 139 \mathrm{ng} / \mathrm{mL}$ for stable IPF, $534 \pm 223$ for CTD-associated IP, $221 \pm 42 \mathrm{ng} / \mathrm{mL}$ for COPD and $150 \pm 32 \mathrm{ng} / \mathrm{mL}$ for healthy volunteers. Thus, sICAM-1 levels were significantly higher in patients with COPD than in healthy volunteers. In patients with stable IPF and CTD-associated IP, sICAM-1 levels were significantly higher than those in healthy volunteers and patients with COPD (Fig. 1). Investigation of possible correlations between biomarkers in patients with stable IPF indicated that sICAM-1 levels exhibited a positive correlation with KL-6 and CRP ( $r$ value $0.41 ; 0.36$ ) (Table 2).

Among the 11 patients with AEx IPF, mean sICAM-1 levels were $645 \pm 247$. Mean sICAM-1 levels were significantly higher in cases with AEx IPF than with stable IPF ( $p=0.0199)$ (Fig. 2). Investigation of possible correlations between biomarkers in patients with AEx IPF indicated that SICAM-1 levels exhibited a positive correlation with only KL-6 (r value 0.82) (Table 3). Comparison of biomarkers in cases with AEx IPF and stable IPF indicated that independent predictors for early

Table 1 Characteristics of study population

\begin{tabular}{|c|c|c|c|c|}
\hline Characteristics & Stable IPF & CTD-associated IP & COPD & Healthy volunteer \\
\hline Subjects & 30 & 7 & 6 & 7 \\
\hline Male/female & $25 / 5$ & $3 / 4^{*}$ & $6 / 0$ & $1 / 6^{* *}$ \\
\hline Age (years) & $72.3 \pm 6.3$ & $73.3 \pm 6.8$ & $75.5 \pm 6.5$ & $26.9 \pm 4.0^{* *}$ \\
\hline \multicolumn{5}{|l|}{ Smoking history } \\
\hline Never/Ex- and current & $7 / 23$ & $3 / 4$ & $0 / 6$ & $6 / 1^{* *}$ \\
\hline \multicolumn{5}{|l|}{ Treatment received } \\
\hline None & 12 & 0 & $\mathrm{~N} / \mathrm{A}$ & $\mathrm{N} / \mathrm{A}$ \\
\hline $\mathrm{N}$-acetylcysteine & 9 & 0 & N/A & N/A \\
\hline Pirfenidone & 2 & 0 & N/A & $\mathrm{N} / \mathrm{A}$ \\
\hline Steroids & 3 & 0 & N/A & N/A \\
\hline Steroids + immunosuppressant & 3 & 5 & N/A & N/A \\
\hline Steroids + Pirfenidone & 1 & 2 & N/A & N/A \\
\hline \multicolumn{5}{|l|}{ Blood tests } \\
\hline $\mathrm{KL}-6(\mathrm{U} / \mathrm{mL})$ & $1174 \pm 1008$ & $951 \pm 544$ & N/A & $\mathrm{N} / \mathrm{A}$ \\
\hline SP-D (ng/mL) & $240 \pm 131$ & $218 \pm 215$ & N/A & $\mathrm{N} / \mathrm{A}$ \\
\hline $\mathrm{WBC}(/ \mu \mathrm{L})$ & $7660 \pm 2290$ & $11000 \pm 2290^{* *}$ & $9270 \pm 2990$ & $\mathrm{~N} / \mathrm{A}$ \\
\hline LDH (IU/L) & $233 \pm 58$ & $246 \pm 55$ & $173 \pm 34^{*}$ & $\mathrm{~N} / \mathrm{A}$ \\
\hline CRP (mg/dL) & $1.00 \pm 2.49$ & $2.00 \pm 2.87$ & $0.8 \pm 1.08$ & $\mathrm{~N} / \mathrm{A}$ \\
\hline \multicolumn{5}{|l|}{ Pulmonary function } \\
\hline VC \% pred (\%) & $78.6 \pm 23.4$ & $75.5 \pm 14.6$ & $74.5 \pm 13.9$ & $\mathrm{~N} / \mathrm{A}$ \\
\hline FVC \% pred (\%) & $78.4 \pm 23.1$ & $74.1 \pm 16.2$ & $70.0 \pm 11.3$ & $\mathrm{~N} / \mathrm{A}$ \\
\hline $\mathrm{FEV}_{1} \%$ pred (\%) & $99.8 \pm 28.1$ & $86.7 \pm 26.7$ & $38.9 \pm 11.7^{* *}$ & $\mathrm{~N} / \mathrm{A}$ \\
\hline $\mathrm{FEV}_{1} / \mathrm{FVC}(\%)$ & $88.1 \pm 6.2$ & $80.0 \pm 11.4$ & $37.8 \pm 8.1^{* *}$ & N/A \\
\hline DLco \% pred (\%) & $74.9 \pm 28.9$ & $56.7 \pm 19.0$ & $94.1 \pm 34.5$ & N/A \\
\hline
\end{tabular}

Data are presented as $\mathrm{n}$ or mean \pm standard deviation, unless otherwise stated. The unpaired t test was used (versus stable IPF)

IPF idiopathic pulmonary fibrosis, CTD-associtated IP connective tissue disease-associated interstitial pneumonia, COPD chronic obstructive pulmonary disease, N/A not available, KL-6 Krebs von den Lungen-6, SP-D surfactant protein D, WBC white blood cell, LDH lactate dehydrogenase, $C R P C$-reactive protein, VC vital capacity, $\%$ pred $\%$ predicted, FVC forced vital capacity, DLco diffusion capacity of the lung for carbon monoxide

${ }^{*} p<0.05,{ }^{* *} p<0.01$ 


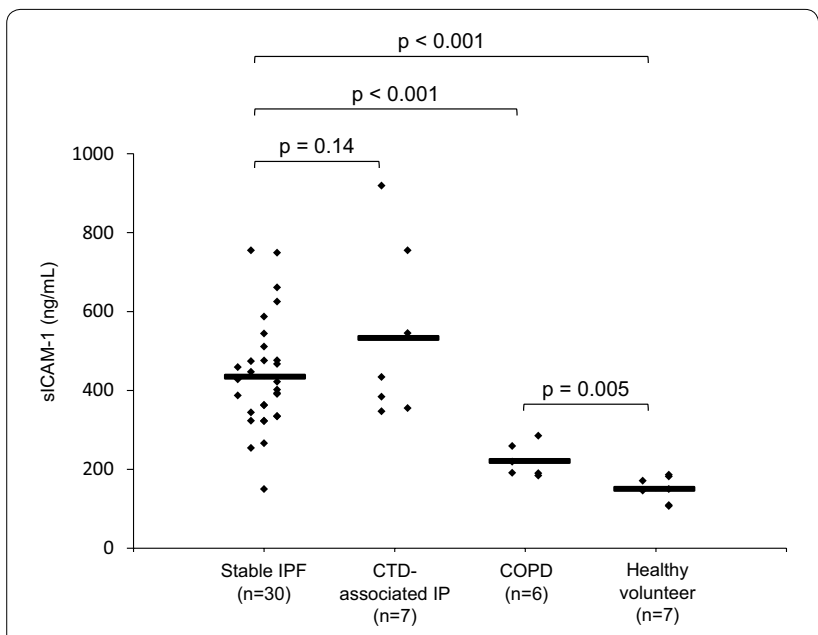

Fig. 1 Levels of sICAM-1 in healthy volunteers and patients with Stable IPF, CTD-associated IP, and COPD. Black lines represent the average values. The unpaired t test was used. s/CAM-1 soluble intercellular adhesion molecule-1, IPF idiopathic pulmonary fibrosis, CTD-associated IP connective tissue disease-associated interstitial pneumonia, COPD chronic obstructive pulmonary disease

Table 2 Correlations between sICAM-1 and other parameters in patients with stable IPF

\begin{tabular}{llr}
\hline Parameters & p value & r value \\
\hline KL-6 & 0.036 & 0.41 \\
SP-D & 0.15 & 0.27 \\
LDH & 0.76 & 0.06 \\
CRP & 0.0496 & 0.36 \\
FVC \% pred & 0.25 & -0.22 \\
DLco \% pred & 0.18 & -0.27 \\
\hline
\end{tabular}

Spearman's rank correlation coefficient was used

sICAM-1 soluble intercellular adhesion molecule-1, IPF idiopathic pulmonary fibrosis, $K L-6$ Krebs von den Lungen-6, SP-D surfactant protein D, $L D H$ lactate dehydrogenase, CRP C-reactive protein, FVC forced vital capacity, \% pred \% predicted, $D L C O$ diffusion capacity of the lung for carbon monoxide

phase of acute exacerbation of IPF were sICAM-1 and CRP (Table 4). The optimal sICAM-1 cutoff for AEx IPF and stable IPF cases was found to be $535 \mathrm{ng} / \mathrm{mL}$ by receiver operating characteristic curve analysis (Fig. 3).

\section{Lung histopathology}

ICAM-1 in lung tissue was investigated using immunohistochemical and immunofluorescence staining. In healthy tissue, ICAM-1 was rarely expressed; however, in patients with stable IPF, ICAM-1 was observed, particularly, in the epithelial cells of cysts and bronchiectasis. ICAM-1 was also observed in some vascular endothelial cells. In cases with CTD-associated IP and AEx IPF, ICAM-1 expression was even stronger than that observed in cases with stable IPF (Figs. 4, 5).

\section{Discussion}

This study demonstrated that sICAM-1 levels were increased in patients with stable IPF and that a positive correlation existed between sICAM- 1 and KL- 6 . This study also indicated that sICAM-1 levels were more useful than KL-6 or SP-D for diagnosing the early phase of acute exacerbation of IPF.

It has previously been reported that sICAM-1 levels are elevated in diseases other than IPF (Greve et al. 1989; Davies et al. 1992; Wegner et al. 1990), and sICAM-1 levels were thought to have little disease specificity to IPF. Few studies have compared sICAM-1 levels in patients with IPF and COPD. In this study, sICAM-1 levels were significantly higher in cases with stable IPF and CTDassociated IP than in cases with COPD. When compared to previous reports on IPF (Takehara et al. 2001; Tsoutsou et al. 2004) and COPD (Oelsner et al. 2013) related to sICAM-1, sICAM-1 levels were higher in patients with IPF than COPD. Differences in ICAM-1 expression in lung tissue were also observed between patients with IPF and COPD in this study, which was consistent with the biomarker results.

Few studies have compared sICAM-1 levels with other interstitial pneumonia markers such as KL-6. In this study, sICAM-1 levels correlated with KL-6 in the stable phase. As KL-6 is a strong prognostic marker of IPF (Yokoyama et al. 2006), sICAM-1 levels might be a useful prognostic indicator. A previous study also reported that sICAM-1 levels could be a prognostic marker of IPF (Richards et al. 2012). Meanwhile, no correlation was observed between SICAM-1 and SP-D. The phenomenon of dissociation of KL- 6 and SP-D has previously been indicated. It has been reported that KL-6 tends to strongly reflect honeycomb lung features, whereas SP-D reflects ground-glass opacities on high-resolution CT (Takahashi et al. 2000). In this study, immunohistochemical staining of stable IPF cases demonstrated a higher degree of ICAM-1 


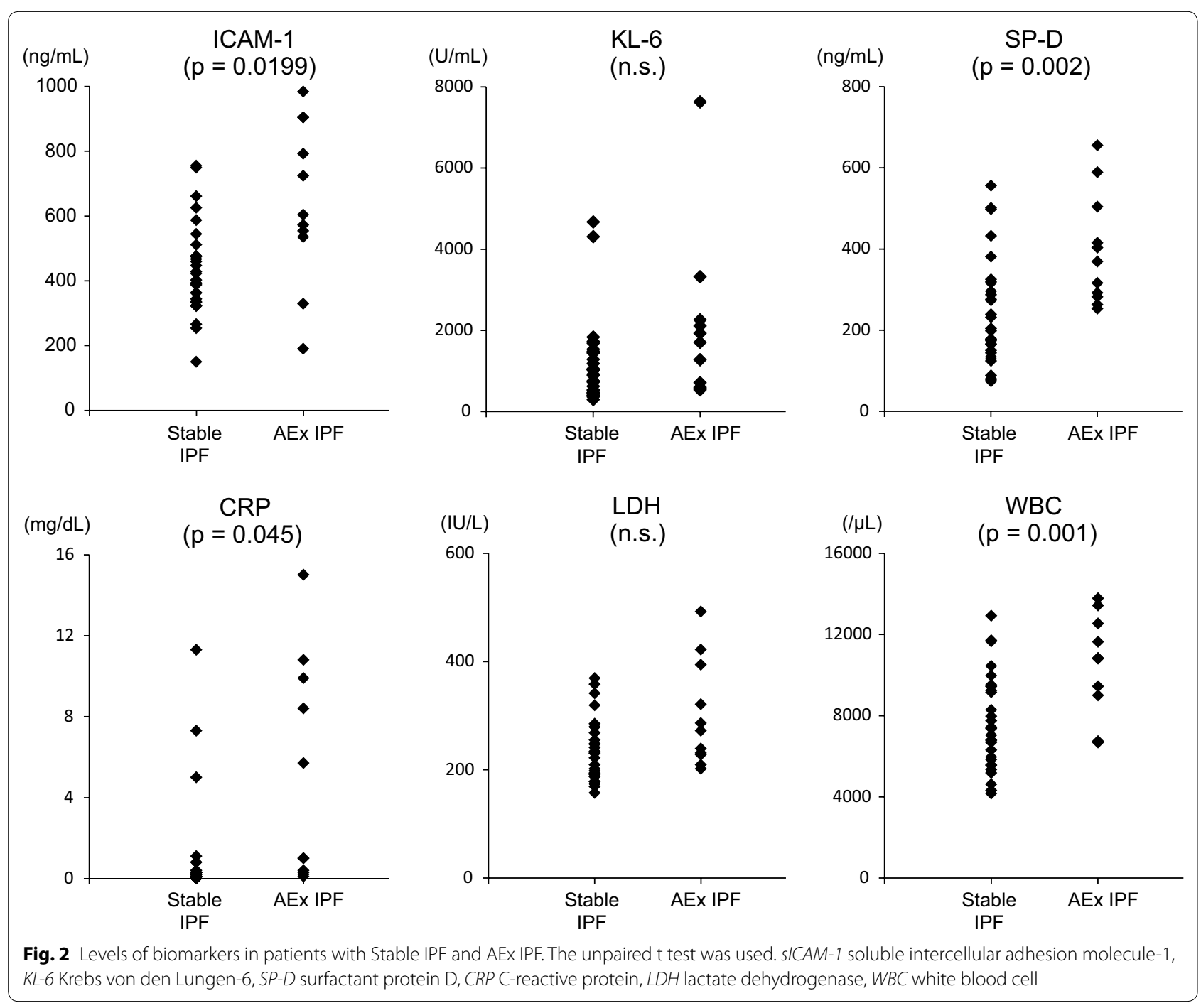

Table 3 Correlations between sICAM-1 and other parameters in patients with early phase of acute exacerbation of IPF

\begin{tabular}{llr}
\hline Parameters & p value & r value \\
\hline KL-6 & 0.002 & 0.82 \\
SP-D & 0.73 & 0.12 \\
LDH & 0.63 & 0.16 \\
CRP & 0.017 & -0.70 \\
WBC & 0.25 & -0.38
\end{tabular}

Spearman's rank correlation coefficient was used

SICAM-1 soluble intercellular adhesion molecule-1, IPF idiopathic pulmonary fibrosis, $K L-6$ Krebs von den Lungen-6, SP-D surfactant protein D, LDH lactate dehydrogenase, CRP C-reactive protein, WBC white blood cell
Table 4 Risk factors of early phase of acute exacerbation of IPF

\begin{tabular}{lcll}
\hline Parameters & p value & Odd ratio & $\mathbf{9 5} \% \mathbf{C l}$ \\
\hline \multicolumn{2}{l}{ Univariate regression analysis } \\
SICAM-1 & 0.007 & 1.0062 & $1.0017-1.0107$ \\
KL-6 & 0.114 & 1.0004 & $0.9999-1.0010$ \\
SP-D & 0.008 & 1.0079 & $1.0020-1.0137$ \\
LDH & 0.024 & 1.0120 & $1.0016-1.0225$ \\
CRP & 0.015 & 1.2831 & $1.0459-1.5696$ \\
WBC & 0.006 & 1.0005 & $1.0001-1.0009$ \\
Multivariate logistic regression analysis & \\
SICAM-1 & 0.028 & 1.0093 & $1.0010-1.0176$ \\
CRP & 0.009 & 1.6069 & $1.1248-2.2957$ \\
\hline
\end{tabular}

IPF idiopathic pulmonary fibrosis, $C /$ confidence interval, sICAM-1 soluble intercellular adhesion molecule-1, KL-6 Krebs von den Lungen-6, SP-D surfactant protein $D, L D H$ lactate dehydrogenase, CRP C-reactive protein, WBC white blood cell 


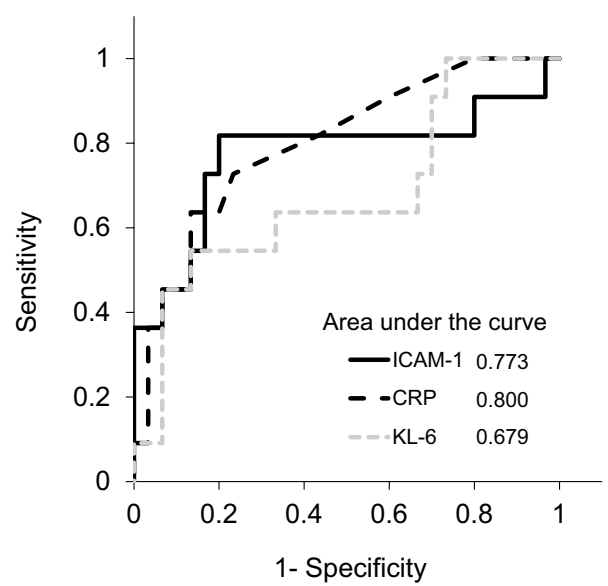

Fig. 3 Receiver operator characteristics curves for identification of patients with acute exacerbation of idiopathic pulmonary fibrosis. s/CAM-1 soluble intercellular adhesion molecule-1, KL-6 Krebs von den Lungen-6, SP-D surfactant protein D

staining in the honeycomb lung or epithelial cells of bronchiectasis than in interstitial cells. Thus, sICAM-1 levels appear to be a biomarker that is more similar to KL-6 than SP-D.

Acute exacerbation of IPF, which occurs in approximately $5-15 \%$ of cases with stable IPF per year, has a poor prognosis with a mortality rate of $50-80 \%$ (Song et al. 2011). Early diagnosis is therefore considered crucial. KL-6 has been widely investigated in the markers of acute exacerbation of IPF (Zhang and Kaminski 2012). It has been reported that KL-6 levels rise in patients with acute exacerbation of IPF (Collard et al. 2010; Ishikawa et al. 2012). On the other hand, KL-6 levels do not always rise in the early phase of acute exacerbation of IPF (Ishizaka et al. 2004; Kakugawa et al. 2013). In this study, sICAM-1 levels were elevated already on the first day diagnosed as acute exacerbation of IPF, suggesting that it could be a biomarker for early phase of acute exacerbation of IPF. Because the expression of ICAM-1 was enhanced in the initial phase of inflammation and early phase of acute respiratory distress syndrome (Schütte et al. 1996; Pugin et al. 1996; Kuppner et al. 1990), sICAM-1 levels may also rise in the early phase of acute exacerbation of IPF.

The limitations of this study include the fact that prognosis could not be investigated due to the small sample size. A previous report demonstrated that sICAM-1 levels were a prognostic factor for IPF (Risse et al. 1994). Hence, verification with large samples of IPF and CTD-associated IP cases is required. Furthermore, the tissue samples used for acute exacerbation cases were from autopsy cases, and therefore, these were not tissue samples from the early phase of acute exacerbation. We also cannot rule out the influence of treatments such as steroid pulse therapy. Despite this, strong ICAM-1 staining in lung tissue was observed in cases with AEx IPF.

In conclusion, sICAM-1 levels in patients of stable IPF strongly correlated with KL-6; sICAM-1 might be a predictive indicator for prognosis. In the early phase of acute exacerbation of IPF, sICAM-1 might be more useful for diagnosis than other interstitial pneumonia markers. In stable and acute phases of IPF, sICAM-1 might be an important biomarker. 

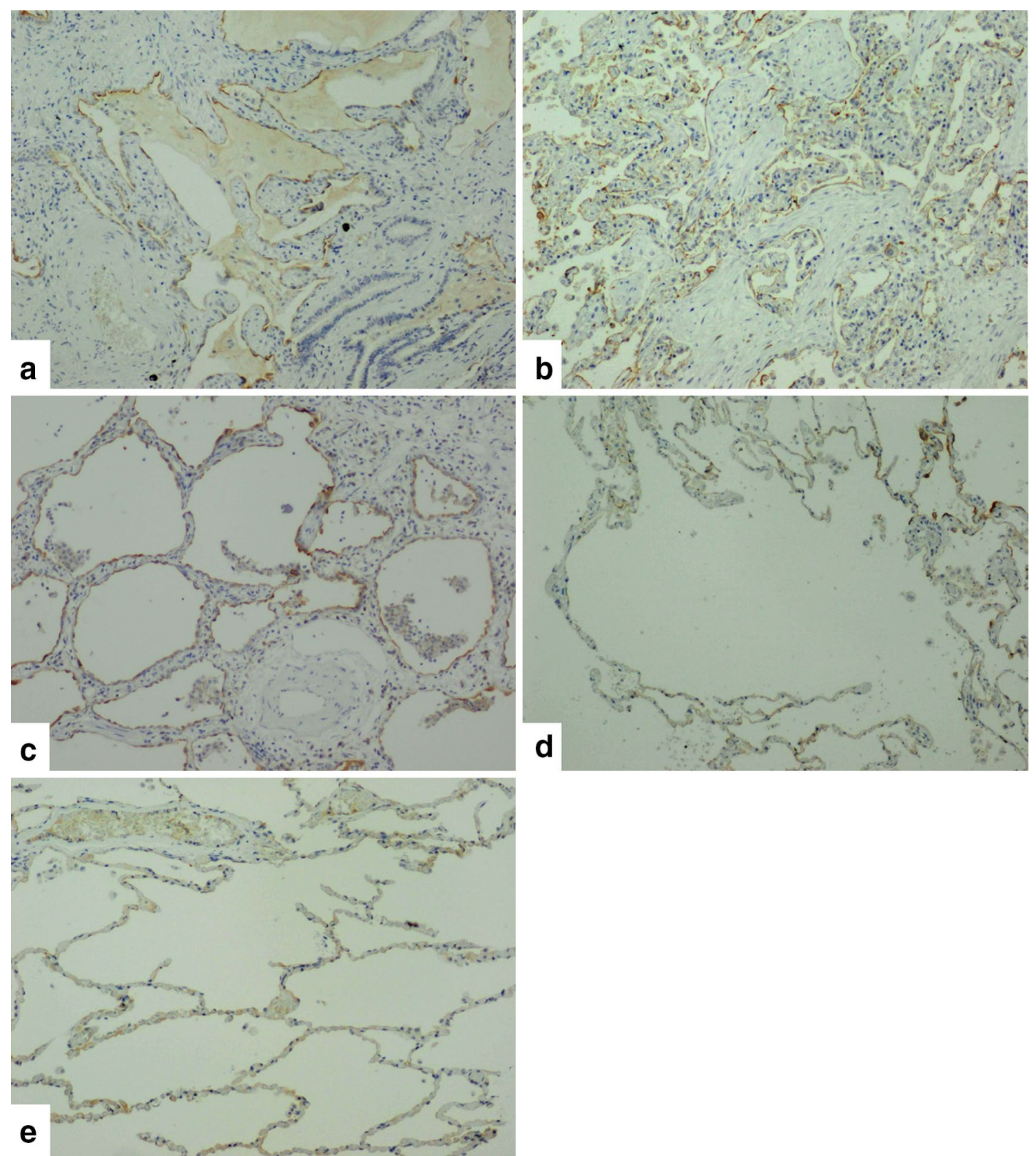

Fig. 4 Immunohistochemical staining for ICAM-1 in the lung tissue. Contrast nuclear staining with hematoxylin was used. Stable IPF (a), AEx IPF (b), CTD-associated IP (c), COPD $(\mathbf{d})$, normal lung $(\mathbf{e})$. Original magnifications, $\times 10$ 

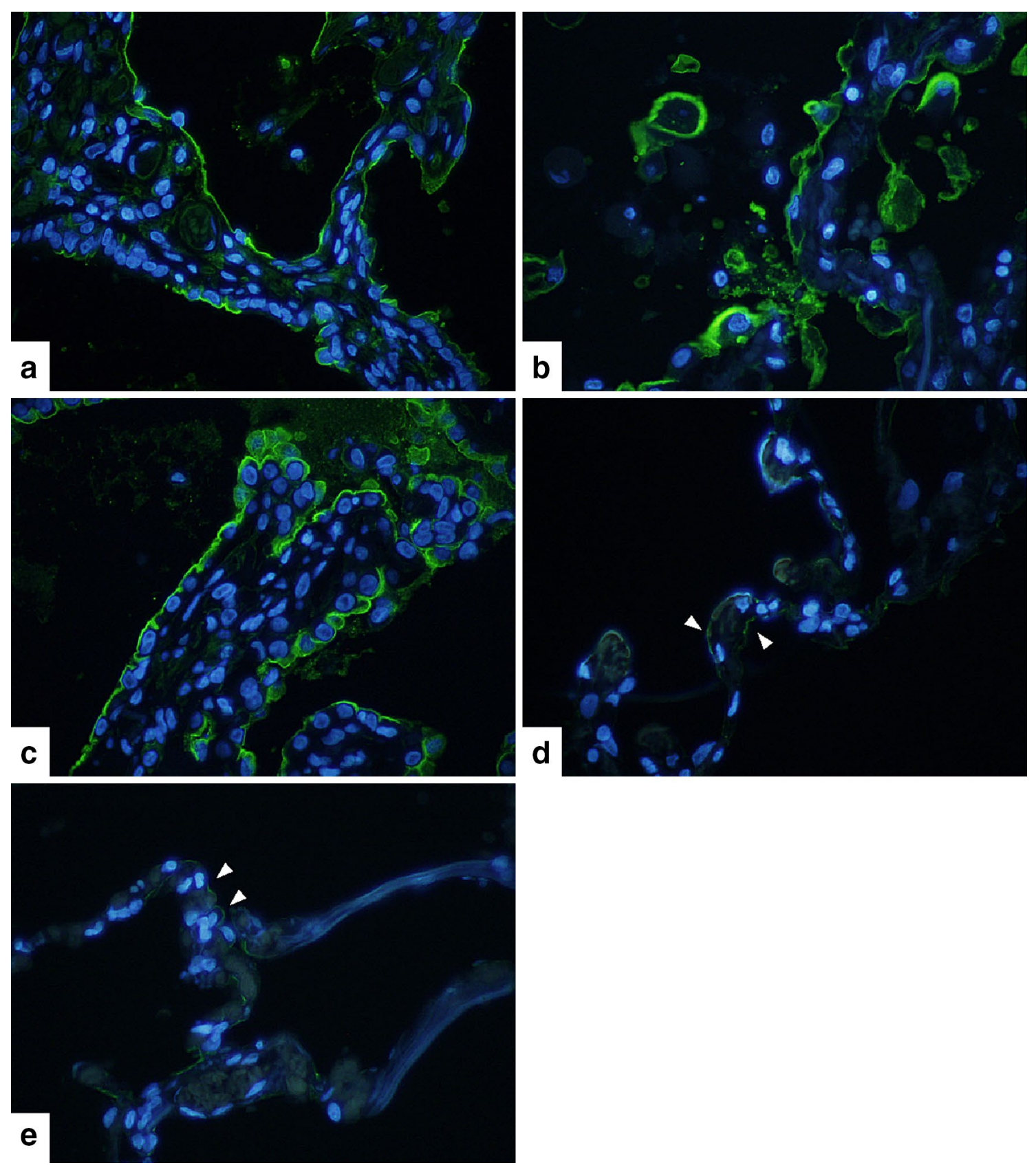

Fig. 5 Immunofluorescence staining for ICAM-1 (green). Contrast nuclear staining with DAPI (blue) was used. Stable IPF (a), AEx IPF (b), CTD-associated IP (c) , COPD (d), normal lung (e). Arrowheads pointed to examples of ICAM-1. Original magnifications, $\times 40$ 


\section{Abbreviations}

sICAM-1: soluble intercellular adhesion molecule-1; IPF: idiopathic pulmonary fibrosis; IL: interleukin; WBC: white blood cell; COPD: chronic obstructive pulmonary disease; CTD-associated IP: connective tissue disease-associated interstitial pneumonia; KL-6: Krebs von den Lungen-6; SP-D: surfactant protein D; CRP: C-reactive protein; LDH: lactate dehydrogenase; CT: computed tomography; UIP: usual interstitial pneumonia; \%FVC: percentage forced expiratory vital capacity; \%DLco: percentage diffusing capacity of the lungs for carbon monoxide; $\mathrm{FEV}_{1}$ : forced expiratory volume in one second.

\section{Authors' contributions}

$\mathrm{RO}, \mathrm{HM}$, and $\mathrm{KA}$ contributed the study design. $\mathrm{RO}, \mathrm{HM}, \mathrm{TO}, \mathrm{RK}, \mathrm{KH}$, and MA collected data. RO, HM, KA, TO, RK, and $\mathrm{KH}$ contributed the analysis of data. RO, $\mathrm{HM}, \mathrm{KA}, \mathrm{TO}, \mathrm{KH}$, and $\mathrm{MA}$ were involved in the drafting of the manuscript. All authors contributed to revise the manuscript. All authors read and approved the final manuscript.

\section{Author details}

1 Department of Respiratory Medicine, Saitama Red Cross Hospital, 8-3-33 Kami-ochiai, Chuo-ku, Saitama 338-8553, Japan. ${ }^{2}$ Department of Respiratory Medicine, Tokyo Medical University Ibaraki Medical Center, 3-20-1 Chuou, Ami, Inashiki, Ibaraki, Japan.

\section{Competing interests}

The authors declare that they have no competing interests.

\section{Funding}

This research did not receive any specific grant.

\section{Consent for publication}

This study was approved by the institutional review board of the Saitama Red Cross Hospital. Informed consent was obtained from all patients.

Received: 4 August 2015 Accepted: 20 October 2015

Published online: 31 October 2015

\section{References}

Albelda SM, Smith CW, Ward PA (1994) Adhesion molecules and inflammatory injury. FASEB J 8:504-512

Collard HR, Calfee CS, Wolters PJ, Song JW, Hong S-B, Brady S, Ishizaka A, Jones KD, King TE Jr, Matthay MA, Kim DS (2010) Plasma biomarker profiles in acute exacerbation of idiopathic pulmonary fibrosis. Am J Physiol Lung Cell Mol Physiol 299:L3-L7

Davies ME, Sharma H, Pigott R (1992) ICAM-1 expression on chondrocytes in rheumatoid arthritis: induction by synovial cytokines. Mediators Inflamm 1:71-74

Greve JM, Davis G, Meyer AM, Forte CP, Yost SC, Marlor CW, Kamarck ME, McClelland A (1989) The major human rhinovirus receptor is ICAM-1. Cell 56:839-847

Hasegawa M, Asano Y, Endo H, Fujimoto M, Goto D, Ihn H, Inoue K, Ishikawa S, Kawaguchi Y, Kuwana M, Ogawa F, Takahashi H, Tanaka S, Sato S, Takehara $\mathrm{K}$ (2014) Serum adhesion molecule levels as prognostic markers in patients with early systemic sclerosis: a multicentre, prospective, observational study. PLoS One 9:e88150

Hubbard AK, Rothlein R (2000) Intercellular adhesion molecule-1 (ICAM-1) expression and cell signaling cascades. Free Radic Biol Med 28:1379-1386

Ishikawa N, Hattori N, Yokoyama A, Kohno N (2012) Utility of KL-6/MUC1 in the clinical management of interstitial lung disease. Respir Investig 50:3-13

Ishizaka A, Matsuda T, Albertine KH, Koh H, Tasaka S, Hasegawa N, Kohno N, Kotani T, Morisaki H, Takeda J, Nakamura M, Fang X, Marrin TR, Matthay MA, Hashimoto S (2004) Elevation of KL-6, a lung epithelial cell marker, in plasma and epithelial lining fluid in acute respiratory distress syndrome. Am J Pysiol Lung Mol Physiol 286:L1088-L1094

Kakugawa T, Yokota S, Ishimatsu Y, Hayashi T, Nakashima S, Hara S, Sakamoto N, Kubota H, Mine M, Matsuoka Y, Mukae H, Nagata K, Kohno S (2013) Serum heat shock protein 47 levels are elevated in acute exacerbation of idiopathic pulmonary fibrosis. Cell Stress Chaperones 18:581-590
Kondoh Y, Taniguchi H, Kawabata Y, Yokoi T, Suzuki K, Takagi K (1993) Acute exacerbation in idiopathic pulmonary fibrosis: analysis of clinical and pathologic findings in three cases. Chest 103:1808-1812

Kuppner MC, van Meir E, Hamou MF, de Tribolet N (1990) Cytokine regulation of intercellular adhesion molecule-1 (ICAM-1) expression on human glioblastoma cells. Clin Exp Immunol 81:142-148

Munro JM, Pober JS, Cotran RS (1989) Tumor necrosis factor and interferongamma induce distinct patterns of endothelial activation and associated leukocyte accumulation in skin of papio anubis. Am J Pathol 135:121-133

Oelsner EC, Pottinger TD, Burkart KM, Allison M, Buxbaum SG, Hansel NN, Kumar R, Larkin EK, Lange LA, Loehr LR, London SJ, O'Connor GT, Papanicolaou G, Petrini MF, Rabinowitz D, Raghavan S, Redline S, Thyagarajan B, Tracy RP, Wilk JB, White WB, Rich SS, Barr RG (2013) Adhesion molecules, endothelin-1 and lung function in seven population-based cohorts. Biomarkers 18:196-203

Pugin J, Ricou B, Steinberg KP, Suter PM, Martin TR (1996) Proinflammatory activity in bronchoalveolar lavage fluids from patients with ARDS, a prominent role for interleukin-1. Am J Respir Crit Care Med 153:1850-1856

Raghu G, Collard HR, Egan JJ, Martinez FJ, Behr J, Brown KK, Colby TV, Cordier JF, Flaherty KR, Lasky JA, Lynch DA, Ryu JH, Swigris JJ, Wells AU, Ancochea J, Bouros D, Carvalho C, Costabel U, Ebina M, Hansell DM, Johkoh T, Kim DS, King TE Jr, Kondoh Y, Myers J, Müller NL, Nicholson AG, Richeldi L, Selman M, Dudden RF, Griss BS, Protzko SL, Schünemann HJ, ATS, ERS, JRS, ALAT Committee on Idiopathic Pulmonary Fibrosis (2011) An official ATS/ ERS/JRS/ALAT statement: idiopathic pulmonary fibrosis: evidence-based guidelines for diagnosis and management. Am J Respir Crit Care Med 183:788-824

Richards TJ, Kaminski N, Baribaud F, Flavin S, Brodmerkel C, Horowitz D, Li K, Choi J, Vuga LJ, Lindell KO, Klesen M, Zhang Y, Gibson KF (2012) Peripheral blood proteins predict mortality in idiopathic pulmonary fibrosis. Am J Respir Crit Care Med 185:67-76

Risse GC, Larsson S, Löfdahl C-G, Andersson BA (1994) Circulating cell adhesion molecules in bronchial lavage and serum in COPD patients with chronic bronchitis. Eur Respir J 7:1673-1677

Schütte H, Lohmeyer J, Rosseau S, Ziegler S, Siebert C, Kielisch H, Pralle H, Grimminger F, Morr H, Seeger W (1996) Bronchoalveolar and systemic cytokine profiles in patients with ARDS, severe pneumonia and cardiogenic pulmonary oedema. Eur Respir J 9:1858-1867

Song JW, Hong SB, Lim CM, Koh Y, Kim DS (2011) Acute exacerbation of idiopathic pulmonary fibrosis: incidence, risk factors and outcome. Eur Respir J 37:356-363

Takahashi H, Fujishima T, Koba H, Murakami S, Kurokawa K, Shibuya Y, Shiratori M, Kuroki Y, Abe $S$ (2000) Serum surfactant proteins A and D as prognostic factors in idiopathic pulmonary fibrosis and their relationship to disease extent. Am Respir Crit Care Med 162:1109-1114

Takehara H, Tada S, Kataoka M, Matsuo K, Ueno Y, Ozaki S, Miyake T, Fujimori Y, Yamadori I, Harada M (2001) Intercellular adhesion molecule-1 in patients with idiopathic interstitial pneumonia. Acta Med Okayama 55:205-211

Tsoutsou PG, Gourgoulianis KI, Petinaki E, Mpaka M, Efremidou S, Maniatis A, Molyvdas PA (2004) ICAM-1, ICAM-2 and ICAM-3 in the sera of patients with idiopathic pulmonary fibrosis. Inflammation 28:359-364

Vogetseder W, Feichtinger H, Schulz TF, Schwaeble W, Tabaczewski P, Mitterer M, Böck G, Marth C, Dapunt O, Mikuz G, Dierich MP (1989) Expression of 7F7-antigen, a human adhesion molecule identical to intercellular adhesion molecule-1 (ICAM-1) in human carcinomas and their stromal fibroblasts. Int J Cancer 43:768-773

Wegner CD, Gundel RH, Reilly P, Letts LG, Rothlein R (1990) Intercellular adhesion molecule-1 (ICAM-1) in the pathogenesis of asthma. Science 247:456-459

Yokoyama A, Kondo K, Nakajima M, Matsushima T, Takahashi T, Nishimura M, Bando M, Sugiyama Y, Totani Y, Ishizuki T, Ichiyasu H, Suga M, Hamada H, Kohno N (2006) Prognostic value of circulating KL-6 in idiopathic pulmonary fiboris. Respirology 11:164-168

Zhang Y, Kaminski N (2012) Biomarkers in idiopathic pulmonary fibrosis. Curr Opin Pulm Med 18:441-446 